\title{
Spectroscopy Analysis and Confirmation of EN31 Steel
}

\author{
D.O.I - 10.51201/Jusst12620 \\ http://doi.org/10.51201/Jusst12620 \\ Ravikant $^{1}$, Sukhdeep S. Dhami ${ }^{2}$ \\ ${ }^{1}$ M.E. Scholar, Department of Mechanical Engineering, National Institute of Technical Teachers Training and \\ Research (NITTTR), Chandigarh (India). \\ ${ }^{2}$ Professor \& Head, Department of Mechanical Engineering, National Institute of Technical Teachers \\ Training and Research (NITTTR), Chandigarh (India).
}

\begin{abstract}
The spectroscopy process involves a large number of techniques in the analysis of a material. The spectroscopy test results involve the various quantitative elements that belong to the composition of the material. The determination of the composition of material helps in getting the exact results during the experiments. The experiment's primary focus is to select the weakly bound metal ions and study these ions' mass in spectroscopy. The elements like carbon and chromium are the secondary targets so that the material can be confirmed by analyzing the exact composition of the ingredients. The observations obtained from this study will play an essential role in finding the authentic material.
\end{abstract}

Keywords: EN31, Elements, Spectrometer, Wavelength, Composition.

\section{INTRODUCTION}

EN31 is a popular grade of alloy steel widely used in the automobile industry to produce axle, roller bearings, spindles, shear blades, molding dies, ball bearings, spinning tools, beading rolls, shafts, studs, bolts, punches \& dies. It is used in high stress and with a large cross-section. It includes aircraft \& general engineering applications for propeller or gear components. The material is applied frequently where a high degree of wear resistance and surface loading is required [9]. The spectroscopy results give the typical composition of EN31, shown in Table 1.

The spectrometer is a scientific instrument used to separate and measure a physical phenomenon's spectral components. The main components are Ions Source \& Mass Analyzer. It measures the continuous variables where some kind of spectral components are somehow mixed. It includes mainly of these types as; Mass Spectrometer, NMR Spectrometer, and Optical Spectrometer. These are the most common types of spectrometers found in various research labs around the world. A spectrometer measures the wavelength \& the frequency of the light and allows us to identify and analyze the atoms in a required sample.

\section{MATERIAL \& METHODS}

The material used for the machining process is EN31. The material is purchased from RJ Alloy Steel, Wazirpur Industrial Area, New Delhi. One piece of the material having a thickness of $13 \mathrm{~mm}$ and dimensions of 50 x $50 \mathrm{~mm}$

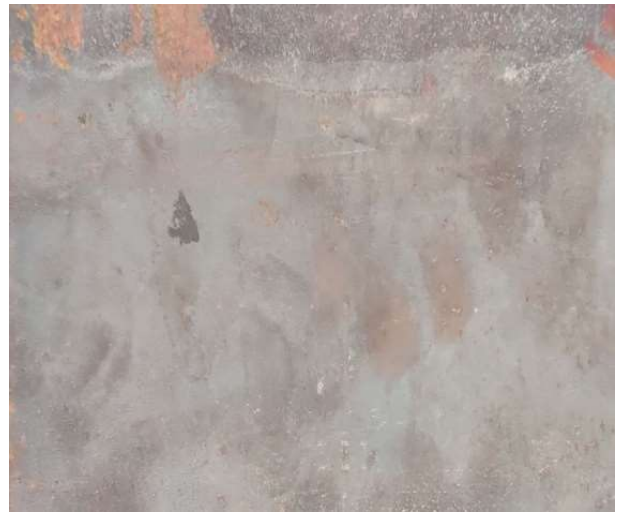

Figure 1. EN31 Specimen

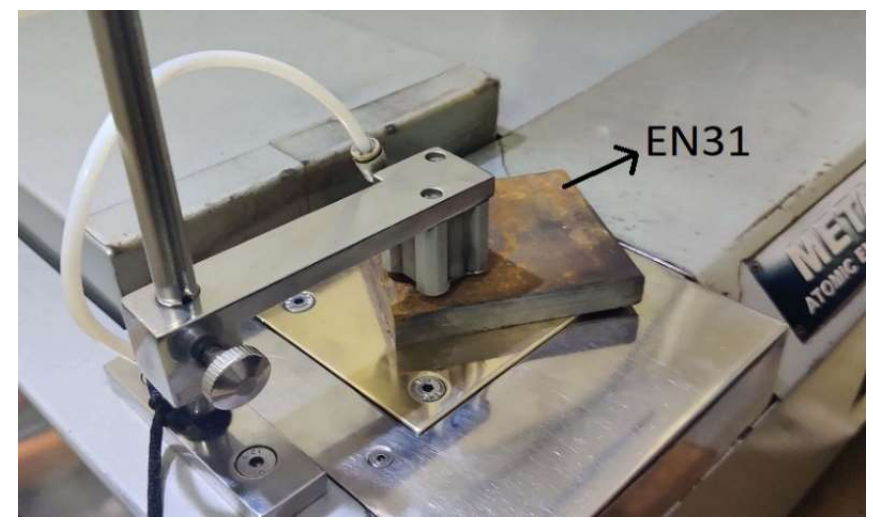

Figure 2. EN31 at METAVISION Spectrometer 
is obtained. This piece is enrolled for confirmation test through spectroscopy. The spectroscopy test is conducted at Gaur Spectro Lab, Wazirpur Industrial Area, New Delhi. The testing material is shown in Fig. 1.

The Mass Spectrometer is selected for the experimentation work. The workpiece is fitted in the spectrometer, as shown in Fig. 2. The spectrometer is made of METAVISION. It has specially designed to obtain a high degree of accuracy and precision at the low detection level. It is capable of detecting the exact level of sub-ppm limits. It analyzes each possible element and also covers each component of the periodic table entirely. It is the most advanced and user-friendly instrument.

Initially, the sample is prepared by cleaning and polishing. As the material is ready, it is placed on the base of the spectrometer. The material's thickness should not be below $2 \mathrm{~mm}$. It must be placed well at the base of the device. The Inductively Coupled Plasma (ICP) is used as an ion source and is utilized to produce the sample ions. Using argon gas, plasma of $10000{ }^{\circ} \mathrm{C}$, as shown in Fig. 3, is created to atomize the sample molecules. Thus, the outer electrons are deprived of the atoms. The material after plasma spark is shown in Fig. 4.

Mass Analyzer accelerates the ions using an electric-magnetic field and hence separates the ions according to mass to charge ratio. The lighter ions will move fast towards the detector, while the heavy ions will move slowly. These traveling ions come in the path of the light. Thus, the spectrometer breaks it into the various spectral components depending upon the ions' traveled path. The divergent light is collimated by a specified concave mirror and directed onto the selected grating. By following this phenomenon, the grating disperses the light's different spectral components at slightly varying angles. Thus, the light is focused by a second concave mirror and hence imaged onto the respective detector, as shown in Fig. 5.

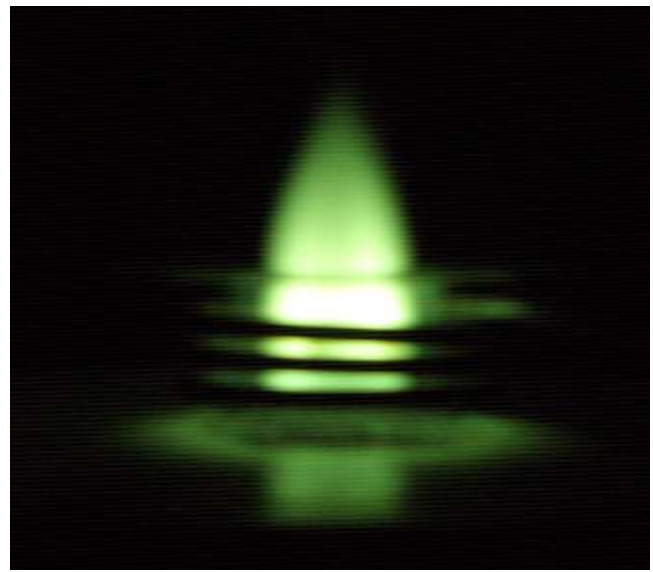

Figure 3. Plasma Spark of $10000^{\circ} \mathrm{C}$

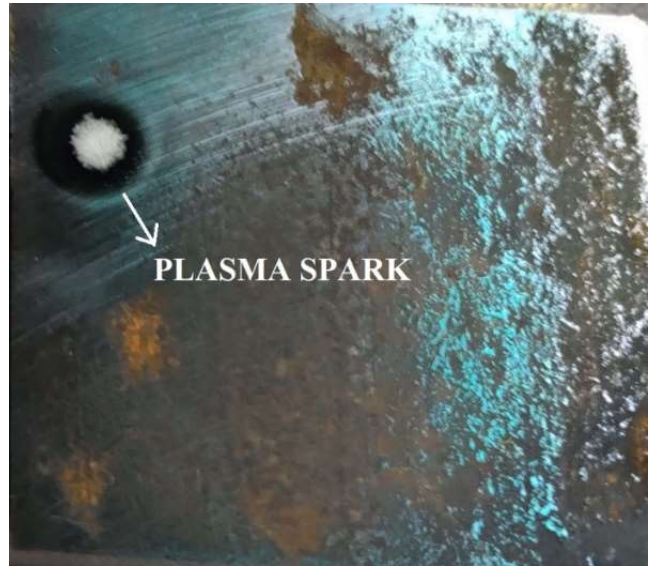

Figure 4. Final Tested Material

Once the light is reflected onto the detector, the photons are produced. These photons are digitized as a function of the wavelength. Hence, it will be read it out and accordingly displays onto the computer screen via USB. Using the various graphical and mathematical calculations, the data obtained is converted quantitatively into the composition (weight percentage) of different elements. In this way, the various compositions are obtained depending upon the observed wavelength of photons. Hence, the received data can be manipulated for many spectroscopic applications.

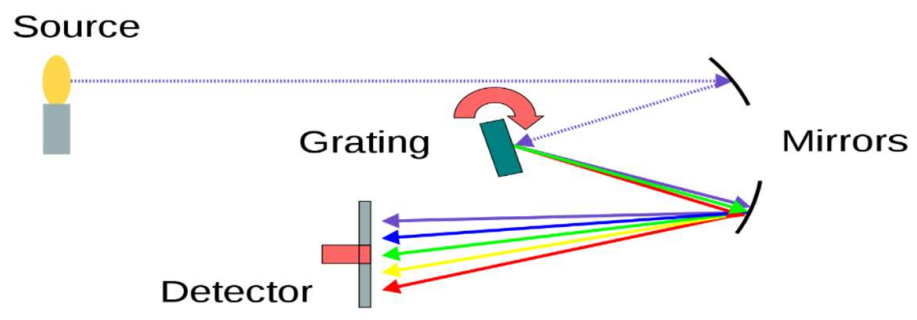

Figure 5. Spectrum Analysis 


\section{RESULTS AND DISCUSSION}

The composition obtained is shown in Table 1. The various elements are shown. The percentage of carbon, chromium, iron, and other components are displayed well. The composition of different elements obtained is matched with the steel specification chart [8]. Thus, by comparing, the material's composition is found within the acceptable limits and hence by analyzing with steel specification chart, it is confirmed as EN31. In this way, the confirmed material can be used further to get the accurate analysis and results.

Table 1. Chemical Composition of EN31 (Weight Percentage)

\begin{tabular}{|c|c|c|c|c|c|c|c|}
\hline Element & $\%$ & Element & $\%$ & Element & $\%$ & Element & $\%$ \\
\hline $\mathbf{C}$ & 0.97 & $\mathrm{Mn}$ & 0.37 & $\mathrm{~S}$ & 0.05 & $\mathrm{Fe}$ & 96.89 \\
\hline $\mathbf{S i}$ & 0.23 & $\mathrm{P}$ & 0.04 & $\mathrm{Cr}$ & 1.04 & $\mathrm{~Pb}$ & 0.02 \\
\hline $\mathrm{Mo}$ & 0.06 & $\mathrm{Al}$ & 0.05 & $\mathrm{~W}$ & 0.01 & $\mathrm{CE}$ & 0 \\
\hline $\mathbf{N i}$ & 0.14 & $\mathrm{Cu}$ & 0 & $\mathrm{Ti}$ & 0 & & \\
\hline $\mathrm{Sn}$ & 0 & $\mathrm{As}$ & 0.02 & $\mathrm{Nb}$ & 0 & & \\
\hline $\mathrm{Co}$ & 0.03 & $\mathrm{~V}$ & 0.04 & $\mathrm{~B}$ & 0.01 & & \\
\hline
\end{tabular}

\section{CONCLUSION}

The material found is confirmed as EN31. A wide variety of elements is obtained. Thus, the confirmation of EN31 plays an essential role in the adequate analysis.

\section{ACKNOWLEDGEMENT}

This experimental work is supported by R.J. Alloy Steel and GAUR Spectro Lab in Wazirpur Industrial Area, New Delhi, India.

\section{REFERENCES}

[1] Wang, Qi, Xie, Lijuan, Ying, Yibin. Overview of imaging methods based on terahertz time-domain spectroscopy, Applied Spectroscopy Reviews, (2021), pp.0570-4928.

[2] Raquel Serrano, Guillermo Grindlay, Luis Gras, Juan Mora. Insight into the origin of carbon matrix effects on the emission signal of atomic lines in inductively coupled plasma optical emission spectrometry, Spectrochimica Acta Part B: Atomic Spectroscopy, (2021), vol 177.

[3] Dinakaran Elango, Anand Kanatti, Wanyan, Akoijam Ranjita Devi \& Akhila Jabeen. Analytical Methods for Iron and Zinc Quantification in Plant Samples, Communications in Soil Science and Plant Analysis, (2021), pp.1-6.

[4] Althobiti, Randa A, Beauchemin, Diane. Direct multi-element analysis of natural toothbrush by electrothermal vaporization into inductively coupled plasma optical emission spectrometry, Journal of Analytical Atomic Spectrometry, (2021), pp.267-9477.

[5] Hu, W., Campuzano-Jost, P., Day, D. A., Nault, B. A., Park, T., Lee, T. \& Jimenez. Ambient Quantification and Size Distributions for Organic Aerosol in Aerosol Mass Spectrometers with the New Capture Vaporizer. ACS Earth and Space Chemistry, 4(5), (2020), pp. 676-689.

[6] Weisbrod, C. R., Anderson, L. C., Greer, J. B., DeHart, C. J., \& Hendrickson. Increased Single-Spectrum TopDown Protein Sequence Coverage in Trapping Mass Spectrometers with Chimeric Ion Loading. Analytical Chemistry, 92(18), (2020), pp. 12193-12200.

[7] Zarubin, I. A., Labusov, V. A., \&Babin. Characteristics of Compact Spectrometers with Diffraction Gratings of Different Types. Inorganic Materials, 56(14), (2020), pp. 1436-1440.

[8] Steel Specifications Chart. Retrieved from < https://www.spectro.in/Steel-Chart.html>(2020), Dec 22.

[9] Harichandra \& Prashanth, Mrudula \& Mathapati, Mahantayya \& Prakash. Evaluation of Mechanical Properties of EN31 steel heat treated using Biodegradable oils, International Journal of Applied Engineering Research, (2015), vol 10.

[10] Trevor L. Hughes, Claire M. Methven, Timothy G.J Jones, Sarah E. Pelham, Philip Fletcher, Christopher Hall. Determining cement composition by Fourier transform infrared spectroscopy, Advanced Cement Based Materials, vol 2, (1995), pp.91-104. 